\title{
Review dan Resetting Skema Overload Shadding Interbus Transformer $500 / 150$ kV 1,3 Gandul dan 2 Kembangan
}

\author{
Ibnu Hajar'; Muhammad Ridho \\ ${ }^{1}$ Institut Teknologi PLN; ${ }^{2}$ Alumni Departemen Elektro, Sekolah Tinggi Teknik PLN \\ ${ }^{1}$ ibnu.hajar@itpln.ac.id
}

\begin{abstract}
Power system protection is one of the most important aspect in power system operation. Power system protection is an attempt to widely prevent the fault over the whole system. One of the power system protection schemes that have been applied by PT. PLN (Persero) to $150 \mathrm{kV}$ Jawa Bali subsystem is Over Load Shedding of Interbus Transformer 500/150 kV. Over Load Shedding scheme has correctly to be set to prevent overload on secondary side of IBT 500/150 kV. Black Out occured on January 2, 2018 at $150 \mathrm{kV}$ subsystem of 1,3 Gandul - 2 Kembangan - Muara Karang is one of the impact caused by incorrect-setting of Over Load Shedding scheme. The purposes of this research are to review the initial setting of Over Load Shedding scheme and to reset it as a follow-up of Black Out event occured in this subsystem. This research is to be done by analyzing the overload points obtained by the simulation of DIgSILENT 14.3.1. This thesis results the new Over Load Scheme setting of IBT 500/150 kV 1 and 3 Gandul those are 3 seconds of pick-up times for the first step and 3,5 seconds of pick-up times for the second step wherein 410,98 MW is necessarily to be shed in 2 steps. Meanwhile, the new Over Load Shedding setting of IBT 500/150kV 2 Kembangan are 2 seconds of pick-up times for the first step and 2,5 seconds of pick-up times for the second step wherein $378,23 \mathrm{MW}$ is necessarily to be shed in 2 steps.
\end{abstract}

Keywords: Electric Power system protection, Over Load Shedding, IBT 500/150kV, DIgSILENT

\begin{abstract}
ABSTRAK
Proteksi sistem tenaga listrik merupakan salah satu aspek yang sangat penting dalam pelaksanaan sistem operasi tenaga listrik. Proteksi sistem tenaga listrik merupakan upaya untuk mencegah dampak gangguan meluas yang dapat mengganggu sistem secara keseluruhan. Salah satu skema proteksi penyelamatan operasi tenaga listrik yang diterapkan PT. PLN (Persero) untuk subsistem $150 \mathrm{kV}$ Jawa - Bali adalah skema Overload Shedding IBT (Interbus Transformer) 500/150 kV. Skema Overload Shedding IBT 500/150 kV harus disetting dengan baik untuk mencegah terjadinya pembebanan berlebih pada sisi sekunder IBT 500/150 kV. Adanya kejadian black out Subsistem 150kV 1,3 Gandul - 2 Kembangan - Muara Karang tanggal 02 Januari 2018 merupakan salah satu dampak akibat kurang baiknya setting skema Overload Shedding tersebut. Tujuan penelitian ini adalah untuk melakukan review dan resetting skema Overload Shedding sebagai tindak lanjut adanya kejadian Black Out pada tanggal 02 Januari 2018. Penelitian ini dilakukan analisa kemungkinan waktu yang mengalami overload melalui simulasi menggunakan aplikasi DIgSILENT 14.3.1. Dari simulasi didapat setting baru skema Overload Shedding yakni untuk skema Overload Shedding IBT 500/150kV 1,3 Gandul beban yang dilepas adalah sebesar 410,98 MW dalam 2 tahap, dengan waktu kerja tahap 1 adalah 3 detik dan tahap 2 adalah 3,5 detik. Untuk skema baru Overload Shedding IBT 500/150kV 2 Kembangan beban yang dilepas sebesar 378,23 MW dalam 2 tahap, dengan waktu kerja tahap 1 adalah 2 detik dan tahap 2 selama 2,5 detik.
\end{abstract}

Kata kunci: Proteksi Sistem Tenaga Listrik, Over Load Shedding, IBT 500/150kV, DIgSILENT 


\section{PENDAHULUAN}

Salah satu skema operasi penyelamatan sistem yang dipakai oleh PT PLN (Persero) adalah OLS (Overload Shedding). Load Shedding adalah proses pelepasan beban terpilih secara sengaja dari sistem tenaga listrik dalam menanggapi kondisi abnormal dalam rangka mempertahankan integritas sisa sistem (IEC ref 603-04-32). OLS (Overload Shedding) adalah operasi pelepasan beban lebih dimana overload pada bagian sistem tertentu dipakai sebagai pemicu. Pola load shedding dengan sensor Overload Relay diterapkan untuk menjaga agar instalasi penyaluran tidak sampai overload bila terjadi perubahan konfigurasi akibat gangguan hubung singkat atau pelepasan suatu pembangkit dalam suatu sistem.

Skema OLS adalah skema yang dipasang pada instalasi yang tidak memenuhi persyaratan N1, dengan tujuan:

1. Mengamankan peralatan dari beban lebih.

2. Menyelamatkan sebagian beban dari efek pemadaman yang lebih besar.

Sebagai contoh, apabila ada 2 IBT 500/150kV menyuplai beban sebesar $500 \mathrm{MW}$, dengan kapasitas maksimal masing-masing IBT sebesar $400 \mathrm{MW}$. Apabila IBT 500/150kV 1 mengalami gangguan sehingga menyebabkan IBT 500/150kV 1 trip, maka IBT 500/150kV 2 akan menanggung beban IBT 500/150kV 2 + IBT 500/150kV 1 sebesar 500 MW. Sebagaimana sudah diketahui bahwa kapasitas maksimal masing - masing 2 IBT 500/150kV adalah sebesar $400 \mathrm{MW}$. Dalam kondisi ini, IBT 500/150kV 2 mengalami Overloading sebesar $100 \mathrm{MW}$, sehingga perlu dilakukan pengurangan beban sebesar $100 \mathrm{MW}$ dengan menggunakan skema Overload Shedding. Skema Overload Shedding diperlukan untuk mengurangi beban IBT 500/150kV 2 menjadi $400 \mathrm{MW}$, sehingga IBT 500/150kV 2 tidak mengalami overloading. Apabila pada IBT 500/150kV 2 tidak dipasang skema Overload Shedding, maka Over Current Relay pada IBT 500/150kV 2 akan bekerja untuk mengtripkan IBT 500/150kV 2. Hal ini akan memicu kaskade pemadaman, karena beban $500 \mathrm{MW}$ akan dipikul penuh oleh pembangkit yang menyuplai subsistem $150 \mathrm{kV}$ tersebut.

Apabila besarnya daya pembangkitan lebih kecil dibandingkan dengan beban subsistem, maka frekuensi subsistem tersebut akan turun. Jika frekuensi sistem turun hingga mencapai besar pickup value UFR (Under Frequency Relay), maka UFR akan mengtripkan pembangkit tersebut yang menyebabkan subsistem $150 \mathrm{kV}$ tersebut akan mengalami pemadaman total (blackout) akibat tidak adanya lagi sumber pemasok daya yang menyuplai daya ke subsistem tersebut.

OLS sistem Jawa Bali menggunakan Over Current Relay (OCR) sebagai sensor utama dalam mendeteksi kenaikan beban. Prinsip kerja OLS sama dengan OCR, hanya saja karakteristik waktu yang digunakan dalam OLS adalah definite dan biasanya mempunyai settingan waktu bertahap. Tahapan waktu ini berfungsi sebagai parameter kebutuhan pembuangan beban yang sesuai dengan kondisi kelebihan beban dari peralatan itu sendiri dan beban yang dibuang dapat berupa beban transformator maupun penghantar. Ada beberapa mekanisme pelepasan beban oleh OLS, yaitu: Pemadaman beban lokal, dan pemadaman beban remote yaitu pelepasan beban pada Gardu Induk lain dengan fasilitas teleproteksi melalui media PLC (Power Line Cable) atau FO (Fiber Optic). Nilai setting beban ditentukan dari nominal terkecil dari bay peralatan yang tidak memenuhi N-1, yakni :

Set I : $1,1 \times I_{n}$ (Ampere)

Set $t$ : Kemampuan thermal peralatan (detik)

Dimana $I_{n}$ adalah arus nominal peralatan terkecil (Ampere).

Agar memenuhi persyaratan sebagai sistem proteksi yang baik, skema OLS perlu disetting dengan baik, dan juga dikoordinasikan dengan peralatan proteksi lainnya. Apabila terjadi salah setting atau miskomunikasi dengan peralatan proteksi lainnya, maka pemadaman beban akan menjadi semakin meluas. Salah satu kejadian yang diakibatkan kurang tepatnya setting skema OLS 


\section{Energi dan Kelistrikan: Jurnal Ilmiah}

Vol. 12, No. 1, Januari - Juni 2020, P-ISSN 1979-0783, E-ISSN 2655-5042

https://doi.org/10.33322/energi.v12i1.942

adalah terjadinya Black Out di subsistem 150 kV 1,3 Gandul - 2 Kembangan - Muara Karang. Pada Setting awal OLS IBT 500/150 kV 1 dan 3 Gandul, kuota beban yang dilepas kurang besar dan juga adanya gangguan pada teleproteksi sehingga memicu OCR (Over Current Relay) IBT 500/150 kV 1,3 Gandul bekerja yang menyebabkan pemadaman semakin meluas.

Pada penelitian ini, fakus pada resetting skema OLS IBT 500/150 kV 1,3 Gandul dan 2 Kembangan, dan melakukan simulasi hasil setting terbaru menggunakan aplikasi DIgSILENT 14.1.3 untuk melihat pengaruh skema OLS terhadap arus sisi sekunder IBT 500/150 kV 1,3 Gandul dan 2 Kembangan, dan juga pengaruhnya terhadap tegangan sistem apabila skema baru OLS bekerja, sehingga bisa didapatkan hasil resetting yang tepat, namun pada artikel ini tidak memasukan pembahasan simulasi dinamik dan tegangan sistem. Dengan melakukan penelitian ini, diharapkan bisa diimplementasikan PT PLN (persero) dalam pengoperasian sistem tenaga listrik.

\section{METODE PENELITIAN}

\subsection{Data-data Penelitian}

Pada penelitian ini, pembuatan skenario OLS diperlukan beban puncak subsistem $150 \mathrm{kV}$ 1,3 Gandul - 2 Kembangan - Muara Karang pada tahun 2017, karena pada beban puncak subsistem, arus beban pada IBT 500/150 kV 1,3 Gandul dan 2 Kembangan berada pada kondisi puncak, sehingga resetting skema OLS pada kondisi beban puncak subsistem dianggap dapat mewakili kondisi beban subsistem pada waktu lainnya, dan setting OLS pada waktu beban puncak dianggap dapat bekerja pada kondisi subsistem lainnya.

Data PT. PLN (Persero) P2B Jawa-Bali, subsistem 150 kV 1,3 Gandul - 2 Kembangan Muara Karang mengalami beban puncaknya di tahun 2017 yaitu 07-12-2017. Data beban yang mengalami kondisi puncak pada tanggal tersebut di subsistem $150 \mathrm{kV}$ Gandul - Kembangan - Muara Karang adalah beban pembangkit, beban IBT 500/150 kV dan beban trafo distribusi.

Pemodelan menggunakan DIgSILENT 14.1.3, data beban pembangkit, beban IBT 500/150 kV dan beban trafo distribusi dirubah nilainya agar mendapatkan kondisi yang serupa kondisi beban puncak pada 07-12-2017, sedangkan data impedansi penghantar tidak mengalami perubahan.

Pemasok daya untuk subsistem 150 kV Gandul - Kembangan - Muara Karang adalah PLTGU Muara Karang, PLTU Muara Karang, IBT 500/150 kV 1 dan 3 Gandul, dan juga IBT 500/150 kV 2 Kembangan. Dari data beban pembangkit, IBT 500/150 kV dan Trafo distribusi subsistem tersebut, penelitian ini memilih beban subsistem pada pukul 12.00 karena pada saat itu pembebanan IBT 500/150kV 1,3 Gandul dan 2 Kembangan berada pada kondisi puncak dan dianggap dapat mewakili kondisi beban subsistem secara keseluruhan selama 24 jam. Data beban tersebut kemudian disimulasikan dengan DIgSILENT 14.1.3.

\subsection{Teknik Analisis}

\subsubsection{Review 24 Jam Setting Awal Skema OLS}

Review 24 jam dilakukan terhadap skema awal OLS IBT 500/150 kV 1,3 Gandul dan 2 Kembangan sebagai tindak lanjut kejadian Blackout pada 02-01-2018. Review dilakukan dengan beberapa kombinasi skenario trip pemasok daya ke subsistem, baik itu IBT 500/150 kV maupun pembangkit.

Kejadian Black-Out Subsistem 150 kV Muara Karang - 1,3 Gandul - 2 Kembangan pada 0201-2018 dipicu oleh keluarnya 2 IBT 500/150 kV (kondisi N-2), yakni keluarnya IBT 500/150 kV 2 Kembangan dari subsistem untuk menyuplai daya ke subsistem lain karena adanya pekerjaan pemeliharaan, dan karena trip nya IBT $500 / 150 \mathrm{kV} 2$ Gandul yang dipicu adanya gangguan pada $O n$ Load Tap Changer (konfigurasi awal subsistem masih menggunakan IBT 500/150 kV 2 Gandul 
sebagai pemasok daya), sehingga pada IBT $500 / 150 \mathrm{kV}$ yang masih bekerja hanya IBT 500/150 kV 1 Gandul (Kondisi N-2 IBT 500/150 kV). Akibat kurangnya beban yang dilepas saat skema OLS IBT 500/150 kV 1 Gandul, maka overload tidak dapat diatasi sehingga IBT 500/150 kV 1 Gandul trip.

Berdasarkan hal tersebut di atas, review 24 jam skema awal OLS, kombinasi trip yang digunakan untuk IBT 500/150 kV adalah trip 2 IBT 500/150 kV. Sedangkan untuk skenario trip pembangkit, dipilih skenario trip PLTGU Muara Karang Blok 2, karena PLTGU Muara Karang Blok 2 memiliki pembebanan yang paling besar dari total seluruh pembangkitan (60,57\%). Dari ketentuan tersebut maka dapat dibuat kombinasi skenario trip pemasok daya Subsistem $150 \mathrm{kV}$ Muara Karang - 1,3 Gandul - 2 Kembangan seperti digambarkan dalam Tabel 1 sebagai berikut:

Tabel 1. Kombinasi skenario trip pemasok daya subsistem 150 kV 1,3 Gandul - 2 Kembangan - Muara Karang

\begin{tabular}{|c|c|c|c|c|c|c|}
\hline No. & $\begin{array}{c}\text { IBT } \\
\mathbf{5 0 0 / 1 5 0} \\
\mathbf{k V ~ 1} \\
\text { Gandul }\end{array}$ & $\begin{array}{c}\text { IBT } \\
\mathbf{5 0 0 / 1 5 0} \\
\mathbf{k V ~ 3} \\
\text { Gandul }\end{array}$ & $\begin{array}{c}\text { IBT 500/150 } \\
\mathbf{k V ~ 2} \\
\text { Kembangan }\end{array}$ & $\begin{array}{c}\text { PLTGU } \\
\text { Muara } \\
\text { Karang } \\
\text { Blok 1 }\end{array}$ & $\begin{array}{c}\text { PLTGU } \\
\text { Muara } \\
\text { Karang } \\
\text { Blok 2 }\end{array}$ & $\begin{array}{c}\text { PLTU } \\
\text { Muara } \\
\text { Karang 4 } \\
\text { dan 5 }\end{array}$ \\
\hline \hline 1 & Aktif & Aktif & Aktif & Aktif & Aktif & Aktif \\
\hline 2 & Aktif & Trip & Trip & Aktif & Aktif & Aktif \\
\hline 3 & Trip & Trip & Aktif & Aktif & Aktif & Aktif \\
\hline 4 & Aktif & Aktif & Aktif & Aktif & Trip & Aktif \\
\hline
\end{tabular}

Dari masing-masing skenario tersebut dibuat grafik beban (MW) dan waktu, dimana untuk waktu harus dilihat selama 24 jam setiap 30 menit, sehingga dengan hasil review ini dapat diketahui pada pukul berapa saja IBT 500/150 kV 1,3 Gandul dan 2 Kembangan mengalami kemungkinan overload walaupun sudah dijalankan skema OLS dan juga supaya hasil resetting OLS lebih akurat dan dapat diandalkan selama 24 jam.

Dalam melakukan review dan resetting skema OLS, terlebih dahulu dicari berapa besarnya batas operasional masing-masing IBT 500/150kV 1,3 Gandul dan 2 Kembangan. Batas operasional masing-masing IBT 500/150kV dapat dicari dengan menggunakan persamaan:

$$
\begin{aligned}
& P_{1-\text { Gandul,max }}=\sqrt{3} V_{s} I_{n} \overline{\cos \varphi}_{1-\text { Gandul }} \\
& P_{3-\text { Gandul,max }}=\sqrt{3} V_{s} I_{n} \overline{\cos \varphi}_{3-\text { Gandul }} \\
& P_{2-\text { Kembangan,max }}=\sqrt{3} V_{s} I_{n} \overline{\cos } \varphi_{2-\text { Kembangan }}
\end{aligned}
$$

\section{Dimana:}

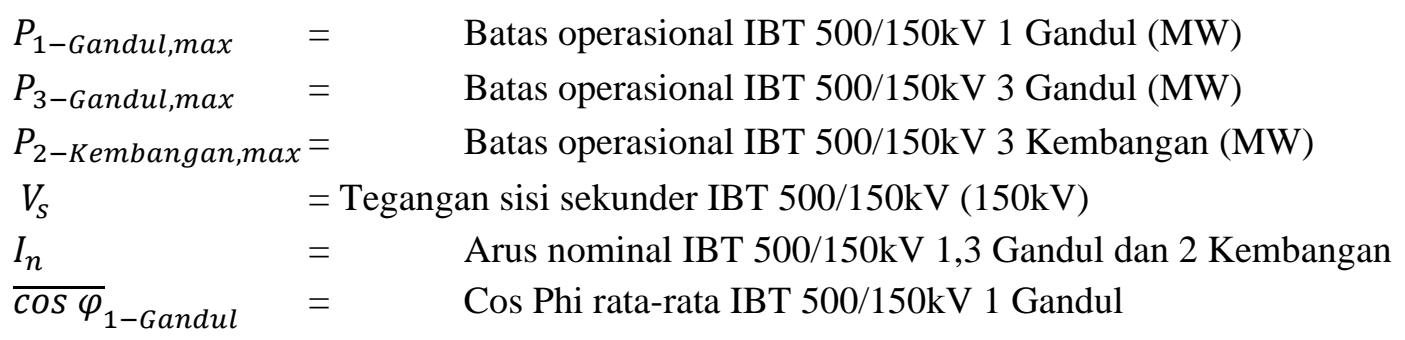




\section{Energi dan Kelistrikan: Jurnal Ilmiah}

Vol. 12, No. 1, Januari - Juni 2020, P-ISSN 1979-0783, E-ISSN 2655-5042

https://doi.org/10.33322/energi.v12i1.942

$$
\begin{array}{ll}
\overline{\cos \varphi}_{3-\text { Gandul }}= & \text { Cos Phi rata-rata IBT 500/150kV } 3 \text { Gandul } \\
\overline{\cos \varphi}_{2-\text { Kembangan }}= & \text { Cos Phi rata-rata IBT 500/150kV } 2 \text { Kembangan }
\end{array}
$$

Pada review 24 jam dan resetting skema OLS perlu diketahui berapa besarnya persentase pembebanan IBT ketika ada pemasok daya yang trip, maupun setelah skema OLS berjalan. Besarnya persentase pembebanan dapat diketahui dengan melakukan perhitungan Load Flow. Dalam review 24 jam dan resetting skema OLS yang dijalankan adalah kombinasi antara skema OLS IBT 500/150kV 1 dan 3 Gandul, skema OLS IBT 500/150kV 2 Kembangan, dan skema OLS IBT 500/150kV 1,3 Gandul + skema OLS IBT 500/150kV 2 Kembangan. Hal ini bertujuan untuk mengetahui berapa besarnya penurunan masing-masing IBT ketika hanya satu skema OLS saja yang berjalan, dan juga untuk mengetahui besarnya kuota beban yang dilepas pada masing-masing skema OLS.

\subsubsection{Resetting Skema OLS}

Resetting skema OLS IBT 500/150 kV 1,3 Gandul dan 2 Kembangan dilakukan dengan cara menghitung besarnya overload salah satu IBT 500/150 kV ketika terjadi skenario trip 2 IBT 500/150 $\mathrm{kV}$. Hal ini berdasarkan pertimbangan bahwa ketika 2 IBT 500/150 kV trip, maka beban total IBT $500 / 150 \mathrm{kV}$ dipikul 100\% oleh satu IBT 500/150 kV saja, sehingga bisa diketahui besarnya overload IBT $500 / 150 \mathrm{kV}$ tersebut. Berbeda halnya dengan skenario trip lain dimana ada persentase pembebanan untuk masing-masing IBT 500/150 kV lain. Besarnya kuota OLS untuk masing-masing IBT 500/150 kV 1,3 Gandul dan 2 Kembangan adalah:

$$
\begin{aligned}
& P_{\text {OLS-Gandul }}=\left(P_{\text {Gandul,normal }}+\Delta P_{\text {sistem }}\right)-P_{\text {Gandul,max }} \\
& P_{\text {OLS-Kembangan }}=\left(P_{2-\text { Kembangan,normal }}+\Delta P_{\text {sistem }}\right)-P_{2-\text { Kembangan,max }}
\end{aligned}
$$

Dimana:

$$
\begin{aligned}
& P_{\text {OLS-Gandul }}=\text { Kuota OLS IBT 500/150kV 1,3 Gandul (MW) } \\
& P_{\text {OLS-Kembangan }}=\text { Kuota OLS IBT 50/150kV } 2 \text { Kembangan }(\mathrm{MW}) \\
& P_{\text {Gandul,normal }}=\text { Beban IBT 500/150kV 1,3 Gandul dalam kondisi normal (MW) } \\
& P_{\text {Gandul,max }}=\text { Beban maksimal IBT 500/150kV 1,3 Gandul (MW) } \\
& P_{2-\text { Kembangan,normal }}=\text { Beban IBT 500/150kV } 2 \text { Kembangan dalam kondisi normal (MW) } \\
& P_{2-\text { Kembangan } \text { max }}=\text { Beban maksimal IBT 500/150kV } 2 \text { Kembangan }(\mathrm{MW}) \\
& \Delta P_{\text {sistem }}=\text { Selisih antara mampu pasok dengan beban subsistem (MW) }
\end{aligned}
$$

PT. PLN (Persero) P2B Jawa - Bali menetapkan bahwa waktu tunda total relay OLS bekerja adalah antara 2 - 4 detik semenjak arus sisi sekunder IBT 500/150kV menyentuh nilai Pick Up, dengan interval masing-masing tahap adalah sebesar 0,5 detik. Hasil resetting skema OLS harus bisa mengatasi overload IBT 500/150kV pada kombinasi skenario trip sebagaimana pada Tabel 1 diatas.

\section{HASIL DAN PEMBAHASAN}

\subsection{Review 24 Jam Skema Awal OLS}

1. Batas Operasional IBT 500/150 kV 1 Gandul

Data diketahui $\cos \varphi$ rata-rata IBT 500/150 kV 1 Gandul adalah sebesar 0,889. $V_{s}$ IBT $500 / 150 \mathrm{kV}$ adalah $150 \mathrm{kV}$, dan $I_{n}$ sebesar $1718 \mathrm{~A}$, maka berdasarkan persamaan 1 batas operasionalnya diperoleh $\boldsymbol{P}_{1-\text { Gandul,max }}=397 \mathbf{M W}$

2. Batas Operasional IBT 500/150 kV 3 Gandul 
Data diketahui $\cos \varphi$ rata-rata IBT $500 / 150 \mathrm{kV} 3$ Gandul adalah sebesar 0,990. $V_{s}$ IBT $500 / 150 \mathrm{kV}$ adalah $150 \mathrm{kV}$, dan $I_{n}$ sebesar $1718 \mathrm{~A}$, dari persamaan 2 didapatkan batas operasionalnya adalah $\boldsymbol{P}_{\mathbf{3}-\text { Gandul, } \max }=442 \mathbf{M W}$

3. Batas Operasional IBT 500/150 kV 2 Kembangan

Data diketahui $\cos \varphi$ rata-rata IBT 500/150 kV 3 Gandul adalah sebesar 0,991. $V_{s}$ IBT $500 / 150 \mathrm{kV}$ adalah $150 \mathrm{kV}$, dan $I_{n}$ sebesar $1718 \mathrm{~A}$, batas operasionalnya diperoleh dengan menggunakan persamaan 3 adalah $P_{2-\text { Kembangan,max }}=443 \mathbf{M W}$

Skema awal OLS berdasarkan kepada Rencana Operasi Tahunan PT. PLN (Persero) P2B Jawa - Bali Tahun 2018 adalah seperti Tabel 2 dan 3 berikut:

Tabel 2. Setting awal skema OLS IBT 500/150 kV 2 Kembangan

\begin{tabular}{|c|}
\hline OLS IBT 500/150 kV 2 Kembangan \\
\hline Setting OLS \\
\hline Tahap 1 \\
\hline Iset = 1900 A $\quad$ tset = 2 detik \\
Skema Trip \\
PMT 150kV PHT Kembangan - New Senayan 1,2 \\
PMT 150kV Trafo-3 GI Kembangan \\
Kuota OLS \\
Tahap 1 = 119 MW
\end{tabular}

Tabel 3. Setting awal skema OLS IBT 500/150 kV 1,3 Gandul

\begin{tabular}{|c|}
\hline OLS IBT 500/150 kV 1,3 Gandul \\
\hline Setting OLS \\
\hline Tahap 1 \\
\hline Iset $=1900 \mathrm{~A}$ \\
\hline Skema Trip \\
\hline PMT 150kV Trafo-1\&3 Petukangan \\
\hline PMT 150kV Trafo-3 Duri Kosambi \\
\hline PMT 150kV Bintaro di GI Petukangan \\
\hline PMT 150kV Trafo-1\&2 Kebon Jeruk \\
\hline Tahap 2 \\
\hline tset $=3,5$ detik \\
\hline Skema Trip \\
\hline PMT 150kV Trafo-2 Duri Kosambi \\
\hline PMT 150kV Grogol 1,2 di GI Duri Kosambi \\
\hline $\begin{array}{l}\text { Kuota OLS } \\
\end{array}$ \\
\hline Tahap $1=251 \mathrm{MW}$ \\
\hline Tahap $2=137 \mathrm{MW}$ \\
\hline
\end{tabular}




\section{Energi dan Kelistrikan: Jurnal Ilmiah}

Vol. 12, No. 1, Januari - Juni 2020, P-ISSN 1979-0783, E-ISSN 2655-5042

https://doi.org/10.33322/energi.v12i1.942

Hasil review 24 jam setting awal skema OLS untuk masing - masing kombinasi skenario trip dapat dilihat pada grafik Gambar 1 di bawah ini:
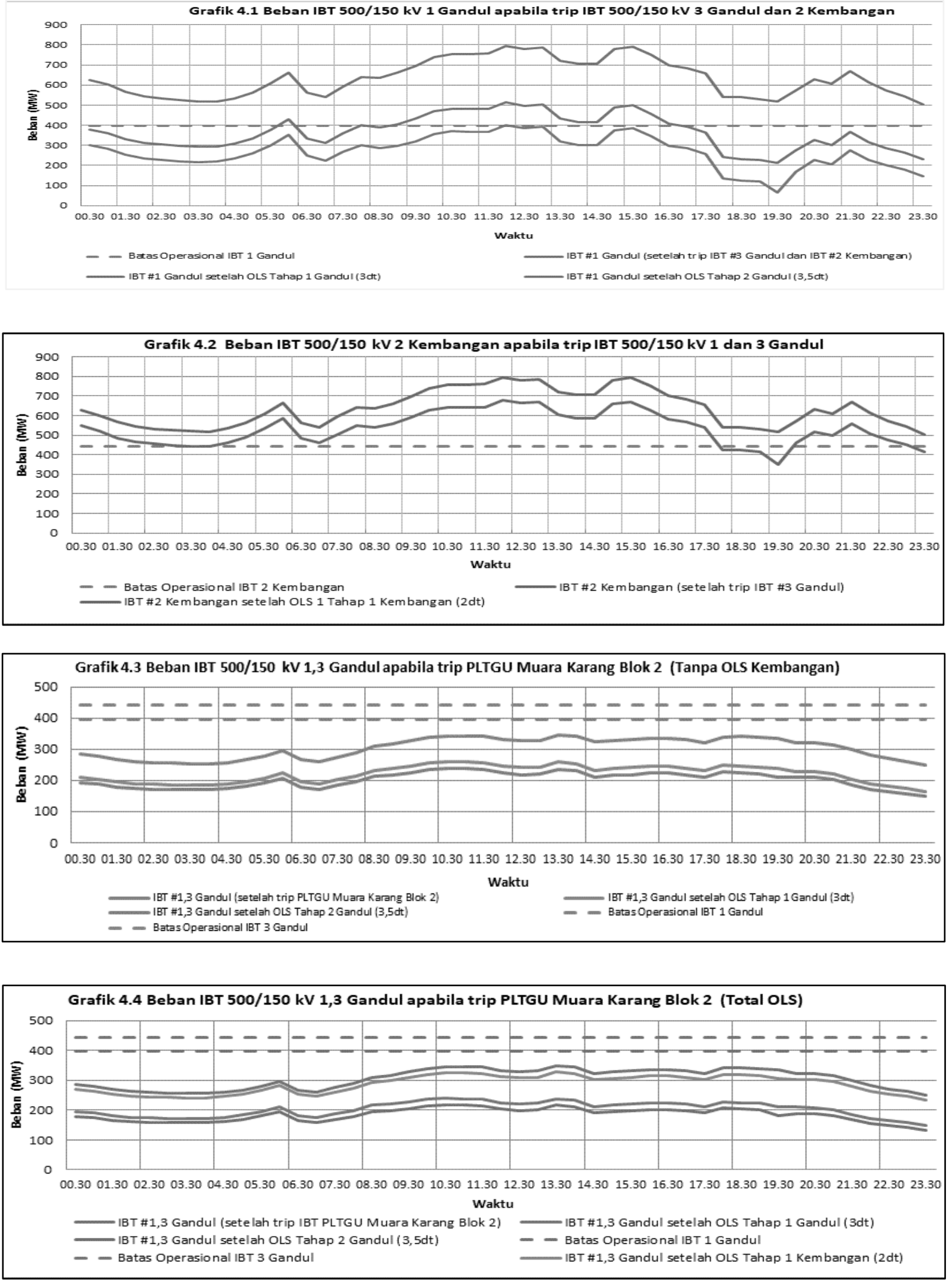

38 | Energi dan Kelistrikan: Jurnal Ilmiah 

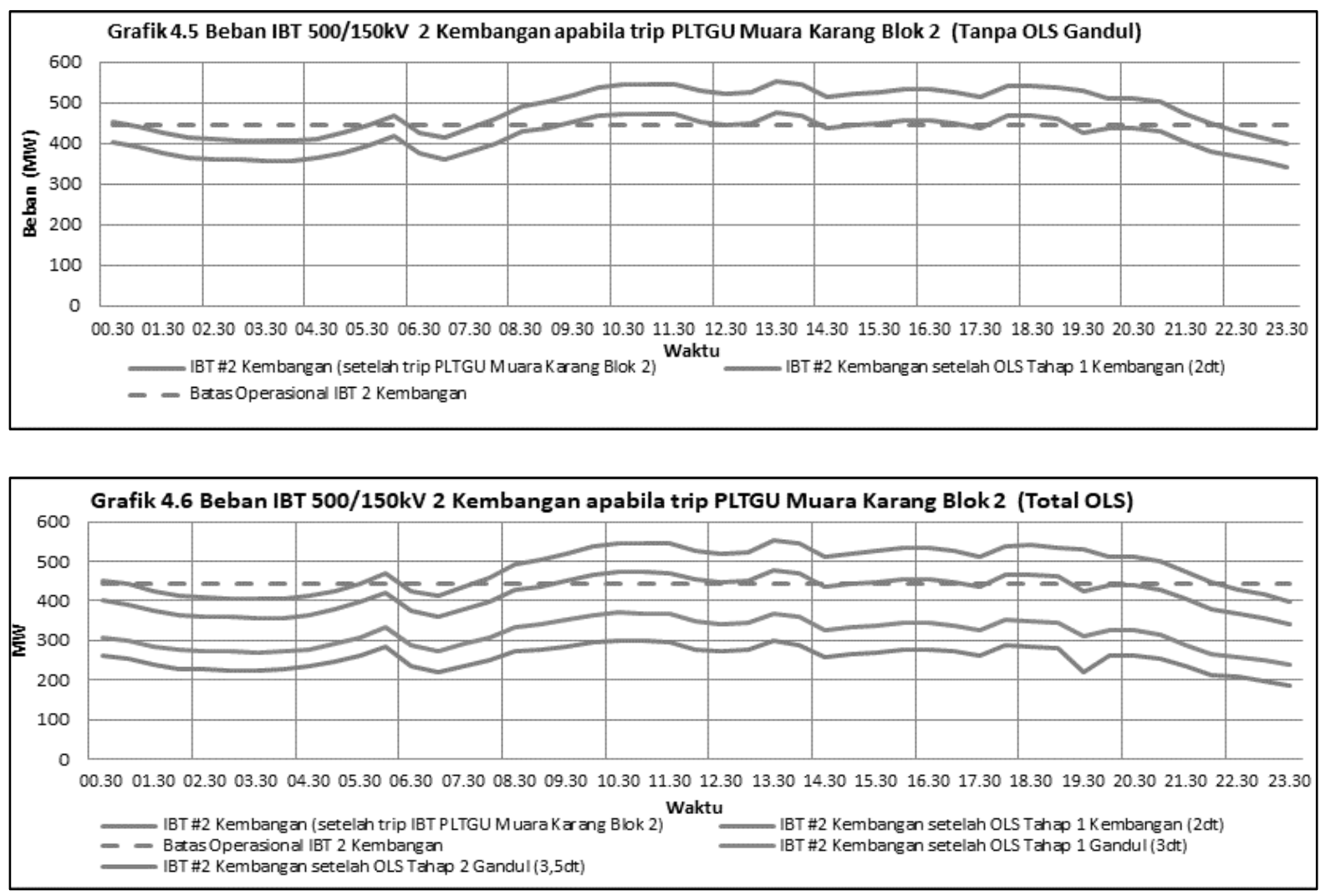

Gambar 1. Review 24 Jam setting awal skema OLS untuk masing - masing kombinasi skenario trip

\subsection{Resetting Skema OLS}

Dari hasil review 24 jam diatas, dapat disimpulkan bahwa beban yang dilepas pada skema OLS IBT 500/150 kV 1,3 Gandul dan 2 Kembangan masih perlu ditambah. Hal ini ditunjukkan pada Gambar 1 grafik 4.1, 4.2 dan 4.5, dimana pembebanan IBT tersebut masih mengalami overload walaupun skema OLS masing - masing IBT 500/150 kV sudah dilaksanakan. Dengan demikian, maka resetting perlu dilakukan untuk menambah beban OLS pada masing-masing skema.

\subsubsection{Penentuan Ulang Kuota Beban Skema OLS}

\section{1) Skema OLS IBT 500/150 kV 1,3 Gandul}

Besarnya beban minimal yang harus dilepas saat skema OLS IBT 500/150 kV 1,3 Gandul ditentukan melalui skenario trip IBT 500/150 kV 1 Gandul dan 2 Kembangan, karena berdasarkan hasil review 24 jam, IBT 500/150 kV 1 Gandul mengalami overload walaupun sudah dilaksanakan skema OLS ketika skenario ini terjadi pada pukul 12.00. Dalam menentukan besarnya beban minimal OLS IBT 500/150 kV 1 dan 3 Gandul, maka digunakan kondisi pembebanan IBT 500/150 kV dan Pembangkit Muara Karang pada pukul 12.00 . 
Tabel 4. Beban subsistem pukul 12.00, 7-12-2017 apabila trip IBT 500/150 kV 3 Gandul dan 2 Kembangan

\begin{tabular}{|c|c|c|c|c|c|c|c|}
\hline $\begin{array}{c}\text { Beban } \\
\text { (MW) IBT 2 } \\
\text { Kembangan }\end{array}$ & $\begin{array}{c}\text { Beban } \\
\text { (MW) IBT } \\
\text { 1 Gandul }\end{array}$ & $\begin{array}{c}\text { Beban } \\
\text { (MW) } \\
\text { IBT 3 }\end{array}$ & $\begin{array}{c}\text { Total } \\
\text { KIT } \\
\text { (MW) }\end{array}$ & $\begin{array}{c}\text { Mam } \\
\text { pu } \\
\text { Pasok }\end{array}$ & $\begin{array}{c}\text { Beban } \\
\text { (MW) } \\
\text { Subsiste }\end{array}$ & $\begin{array}{c}\text { Selisih } \\
\text { (MW) }\end{array}$ & \\
\hline 0 & 234 & 0 & 622 & 896 & 1456 & -560 & \\
\hline
\end{tabular}

Dari Tabel 4 diatas, mampu pasok subsistem ketika trip IBT 500/150 kV 2 Kembangan dan 3 Gandul adalah $896 \mathrm{MW}$, dengan selisih $560 \mathrm{MW}$ terhadap mampu beban subsistem. Pada saat IBT 500/150 kV 1 Gandul dan 2 Kembangan trip, beban sebesar 560 MW yang awalnya dipasok oleh IBT 500/150 kV 1 Gandul dan 2 Kembangan, dipasok sepenuhnya oleh IBT 500/150 kV 1 Gandul. Apabila batas operasional IBT 500/150 kV 1 Gandul adalah 397 MW, maka beban yang harus dilepas pada OLS IBT 500/150 kV 1 Gandul (P $\boldsymbol{P}_{\text {oLS }- \text { Gandul }}$ ) adalah berdasarkan persamaan (4) sebesar 397 MW.

Beban 397 MW pada skema baru OLS IBT 500/150 kV 1,3 Gandul diperoleh dari beban transformator distribusi Subsistem 150kV Muara Karang - 1,3 Gandul - 2 Kembangan pukul 12.00. Skema ini diberikan dalam Tabel 5 di bawah ini:

Tabel 5. Resetting skema OLS IBT 500/150 kV 1 dan 3 Gandul

\begin{tabular}{|c|}
\hline OLS IBT 500/150 kV 1,3 Gandul \\
\hline Setting OLS \\
\hline Tahap 1 \\
\hline Iset $=1900 \mathrm{~A}$ \\
\hline Skema Trip \\
\hline PMT 150kV Trafo-1\&3 Petukangan \\
\hline PMT 150kV Trafo-3 Duri Kosambi \\
\hline PMT 150kV Bintaro di GI Petukangan \\
\hline PMT 150kV Trafo-1\&2 Kebon Jeruk \\
\hline Tahap 2 \\
\hline tset $=3,5$ detik \\
\hline Skema Trip \\
\hline PMT 150kV Trafo-2 Duri Kosambi \\
\hline PMT 150kV Grogol 1,2 di GI Duri Kosambi \\
\hline PMT 150kV Trafo-3 Karet Baru \\
\hline PMT 150kV Trafo-4 Petukangan \\
\hline Kuota OLS \\
\hline Total beban dilepas $=410,98 \mathrm{MW}$ \\
\hline
\end{tabular}

\section{2) Skema OLS IBT 500/150 kV 2 Kembangan}

Besarnya beban minimal yang harus dilepas saat skema OLS IBT 500/150 kV 2 Kembangan ditentukan melalui skenario trip IBT 500/150 kV 1 dan 3 Gandul, karena berdasarkan hasil review 24 jam, IBT 500/150 kV 1 Kembangan mengalami overload walaupun sudah dilaksanakan skema OLS ketika skenario ini terjadi pada pukul 12.00. Besarnya beban yang dilepas pada skema baru OLS IBT 500/150 kV 2 Kembangan juga harus bisa mengatasi overload ketika trip PLTGU Muara Karang Blok 2. Dalam menentukan besarnya beban minimal OLS IBT 500/150 kV 2 Kembangan, maka 
digunakan kondisi pembebanan IBT 500/150 kV dan Pembangkit Muara Karang pada pukul 12.00 .

Tabel 6. Beban subsistem pada pukul 12.00, 7-12-2017 Apabila Trip IBT 500/150 kV 1 dan 3 Gandul

\begin{tabular}{|c|c|c|c|c|c|c|}
\hline $\begin{array}{c}\text { Beban (MW) } \\
\text { IBT 2 } \\
\text { Kembangan }\end{array}$ & $\begin{array}{c}\text { Beban } \\
\text { (MW) IBT } \\
\text { 1 Gandul }\end{array}$ & $\begin{array}{c}\text { Beban } \\
\text { (MW) IBT } \\
\text { 3 Gandul }\end{array}$ & $\begin{array}{c}\text { Total } \\
\text { KIT } \\
\text { (MW) }\end{array}$ & $\begin{array}{c}\text { Mampu } \\
\text { Pasok }\end{array}$ & $\begin{array}{c}\text { Beban (MW) } \\
\text { Subsistem }\end{array}$ & $\begin{array}{c}\text { Selisih } \\
\text { (MW) }\end{array}$ \\
\hline 240 & 0 & 0 & 662 & 902 & 1456 & -554 \\
\hline
\end{tabular}

Dari Tabel 8 diatas, mampu pasok subsistem ketika trip IBT 500/150 kV 1 dan 3 Gandul adalah 902 MW, dengan selisih 554 MW terhadap beban subsistem. Pada saat IBT 500/150 kV 1 dan 3 Gandul trip, beban sebesar 554 MW yang awalnya dipasok oleh IBT 500/150 kV 1 dan 3 Gandul, dipasok sepenuhnya oleh IBT 500/150 kV 2 Kembangan. Apabila batas operasional IBT 500/150 kV 2 Kembangan adalah 443 MW, maka beban yang harus dilepas pada OLS IBT 500/150 kV 2 Kembangan berdasarkan persamaan (5) adalah $\boldsymbol{P}_{\text {oLS-Kembangan }}=\mathbf{3 5 1} \mathbf{M W}$

Beban 351 MW pada skema baru OLS IBT 500/150 kV 2 Kembangan diperoleh dari beban transformator distribusi Subsistem 150kV Muara Karang - 1,3 Gandul - 2 Kembangan pukul 12.00. Skema baru ini diberikan dalam Tabel 7 berikut:

Tabel 7. Resetting skema OLS IBT 500/150 kV 2 Kembangan

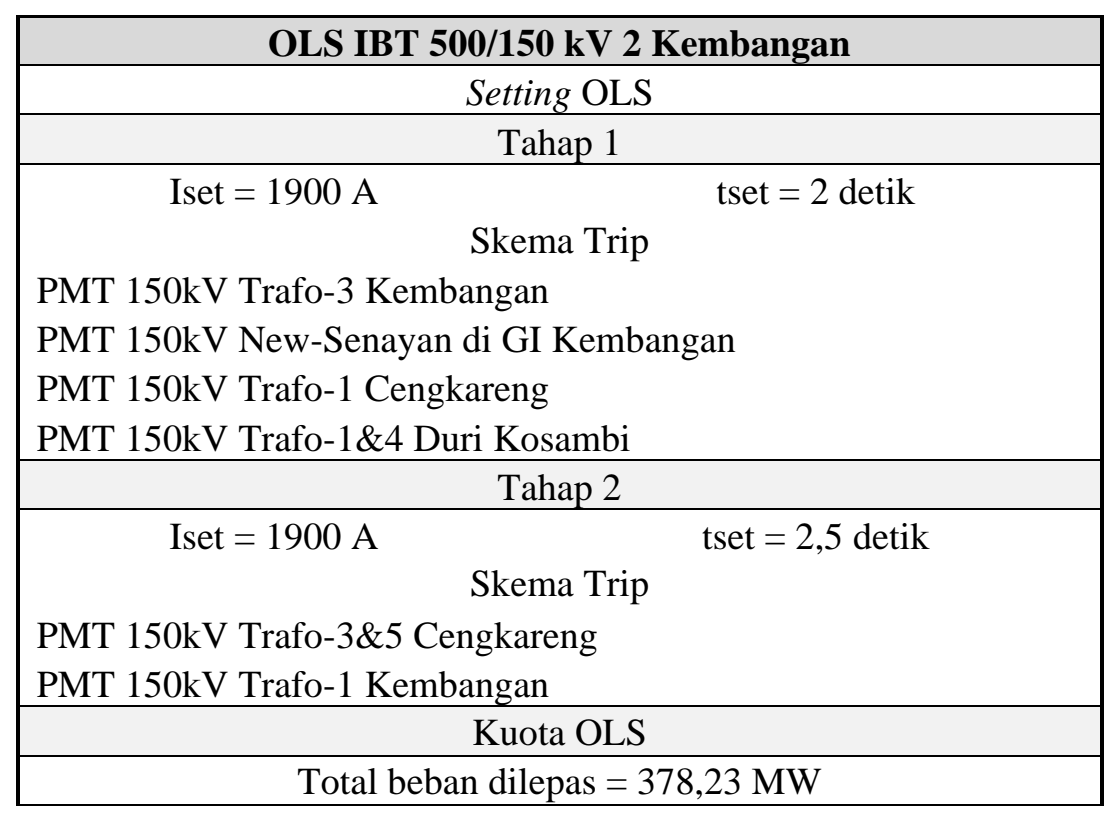

\section{KESIMPULAN DAN SARAN}

Kesimpulan yang dapat diambil dari penelitian ini adalah sebagai berikut:

1. Berdasarkan hasil tinjau ulang 24 jam terhadap skema awal Overload Shedding IBT 500/150 kV 1,3 Gandul dan 2 Kembangan, maka diperlukan setting ulang untuk penambahan beban yang dilepas dengan tujuan mengantisipasi overload IBT 500/150 kV 1,3 Gandul dan 2 Kembangan apabila ada pemasok daya Subsistem 150kV 1,3 Gandul - 2 Kembangan - Muara Karang yang trip.

2. Pada skema baru OverLoad Shedding IBT $500 / 150 \mathrm{kV} 1$ dan 3 Gandul, beban yang dilepas sebesar 410,98 MW dalam 2 tahap, dimana untuk tahap 1 memerlukan waktu tunda selama 
3 detik dan tahap 2 memerlukan waktu tunda selama 3,5 detik. Sedangkan pada skema baru OverLoad Shedding IBT 500/150 kV 2 Kembangan, beban yang dilepas sebesar 378,23 MW dalam 2 tahap, untuk tahap 1 memerlukan waktu tunda selama 2 detik dan tahap 2 memerlukan waktu tunda selama 2,5 detik.

\section{UCAPAN TERIMAKASIH}

Penulis mengucapkan terima kasih kepada PT. PLN (Persero) P2B Jawa - Bali yang mengizinkan kami melakukan penelitian dan memberikan data-data yang diperlukan dalam penelitian ini.

\section{DAFTAR PUSTAKA}

[1] Kementrian Energi dan Sumber Daya Mineral. (1917). Rencana Usaha Penyediaan Tenaga Listrik (2018-2027). PT. PLN (Persero).

[2] Marsudi, D. (2016). Operasi Sistem Tenaga Listrik (Edisi Ketiga). Yogyakarta: Graha Ilmu.

[3] PT. PLN (Persero) P2B Jawa-Bali. (2015). Defense Scheme Sistem Jawa Bali (Bagian A). Gandul: Bidang Operasi Sistem.

[4] PT. PLN (Persero). (2013). Pedoman Sistem Proteksi Transmisi dan Gardu Induk Jawa Bali (Edisi Pertama).

[5] Sarimun N, Wahyudi. (2016). Proteksi Sistem Distribusi Tenaga Listrik (Edisi Kedua). Bekasi Barat: Penerbit Garamond.

[6] Weedy, B.M., Cory, B.J. (2012). Electric Power System. West Susex, United Kingdom: A Wiley-Interscience Publication, John Wiley \& Sons. 